\title{
The inter-scale behaviour of two natural scaly clays
}

\author{
V. NARDELLI*, M. R. COOP $\ddagger$ C. VITONE† and S. CHEN*
}

\begin{abstract}
This paper describes the results of an experimental investigation of the inter-scale behaviour of two natural scaly clays. These have been tested by means of a custom-made inter-particle loading apparatus, which has enabled their mechanical response to be studied in both compression and shearing. The main features of the micromechanical behaviour of these clays have been compared, focusing on the influence of their composition, and the results are compared with those obtained testing the same materials using other devices (triaxial and ring shear apparatus). The results have shown that, contrary to expectations, the surfaces of the scales are not residual shear surfaces and the inter-scale angle of shearing resistance is actually closer to critical state or post-peak angles measured in conventional tests.
\end{abstract}

KEYWORDS: clays; friction; shear strength; stiffness

ICE Publishing: all rights reserved

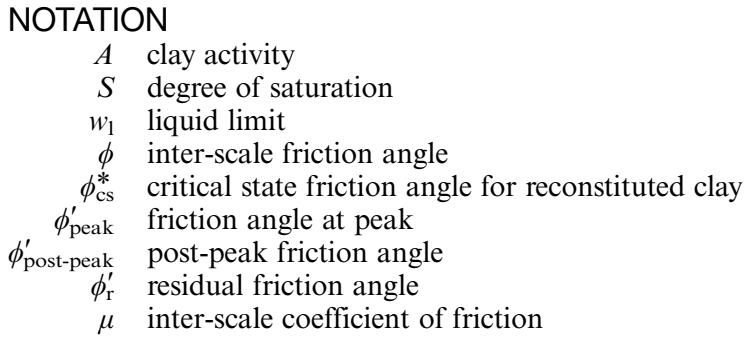

\section{INTRODUCTION}

Scaly clays are natural materials characterised by an intensely fissured mesostructure, which originate from different geological processes, such as tectonic deformations, bulk shearing, submarine gravity sliding, often more recently modified by erosion and weathering. Generally, these materials appear as flaky aggregates made up of small elements called scales (Figs 1(a) and 1(b)), which are visible to the naked eye and have dimensions that range from millimetres to centimetres. Clay scales usually have a flat shape and feature polished, shiny or waxy surfaces (Vannucchi et al., 2003).

Although these materials are made up of distinct elements, the scales, their macro-scale behaviour usually is interpreted by means of continuum mechanics - for example, Cotecchia \& Santaloia (2003) and Vitone \& Cotecchia (2011), who interpreted the mechanical behaviour of intensely fissured clays within the framework of critical state soil mechanics. Vitone et al. (2013) observed that pre-existing fissures play an important role in the strain localisation while shearing samples of scaly clay in a plane strain apparatus. Vitone \& Cotecchia (2011) introduced a fissuring characterisation chart, in order to classify and evaluate the fissuring identity (F-ID) of the fissured clays with respect to those features that affect their mechanical behaviour, such as intensity $(I)$ and orientation $(F)$ of fissures.

Manuscript received 27 April 2016; first decision 16 June 2016; accepted 24 June 2016.

Published online at www.geotechniqueletters.com on 13 July 2016.

${ }^{*}$ City University of Hong Kong, Kowloon Tong, Hong Kong $†$ Politecnico di Bari, Bari, Italy

University College London, UK. Formerly City University of Hong Kong
Previous experimental work at the micro-scale level has focused on the micromechanical behaviour of sands, especially after these started to be studied by means of discrete mechanics (Cundall \& Strack, 1979). Most of these works have examined the strength of sand particles (e.g. Nakata et al., 1999), while others have investigated the contact behaviour (Horn \& Deere, 1962; Skinner, 1969; Cavarretta et al., 2010; Senetakis et al., 2013). However, it should be emphasised that while this work on sands has tested individual particles, the current work is 'micro' only in the sense that small structural elements of natural clays have been tested, not single particles.

The materials tested in this work are the scaly clays from Santa Croce di Magliano (SCM) and Pisciolo (PS), which are two localities within the southern Apennines of Italy. They both belong to the so-called 'structurally complex formations' (Croce, 1971; Esu, 1977), which are typically characterised by a fissured mesostructure originating from very large displacements (of the order of many kilometres) related to regional tectonics. SCM clay belongs to the Red Flysch formation (Oligocene-Miocene, Dazzaro \& Rapisardi, 1996), while the PS clay sample tested has been ascribed to the upper unit of the Paola Doce formation (late Oligocene-lower Miocene, Cotecchia et al., 2015).

\section{EQUIPMENT, MATERIALS TESTED AND PROCEDURES Inter-particle loading apparatus}

The micromechanical experiments were carried out by means of the inter-particle loading apparatus (Fig. 2), which is a custom-built device originally designed to investigate the contact behaviour of sands (Senetakis \& Coop, 2014). This is capable of applying different combinations of either forces or displacements at the contacts of a pair of soil particles in three directions. The apparatus was modified in order to increase the number of testing modes, minimise its compliance and improve the accuracy of the displacement measurements (Nardelli \& Coop, 2015).

The apparatus consists of a stiff stainless steel loading frame, a stainless steel sled and three loading arms ( $a$ and $b$ in Fig. 2). One loading arm is oriented along the vertical direction while the other two are in orthogonal horizontal directions. Each loading arm was comprised of a micro linear actuator (Fig. 2(c)) and a load cell, connected to the sled and 

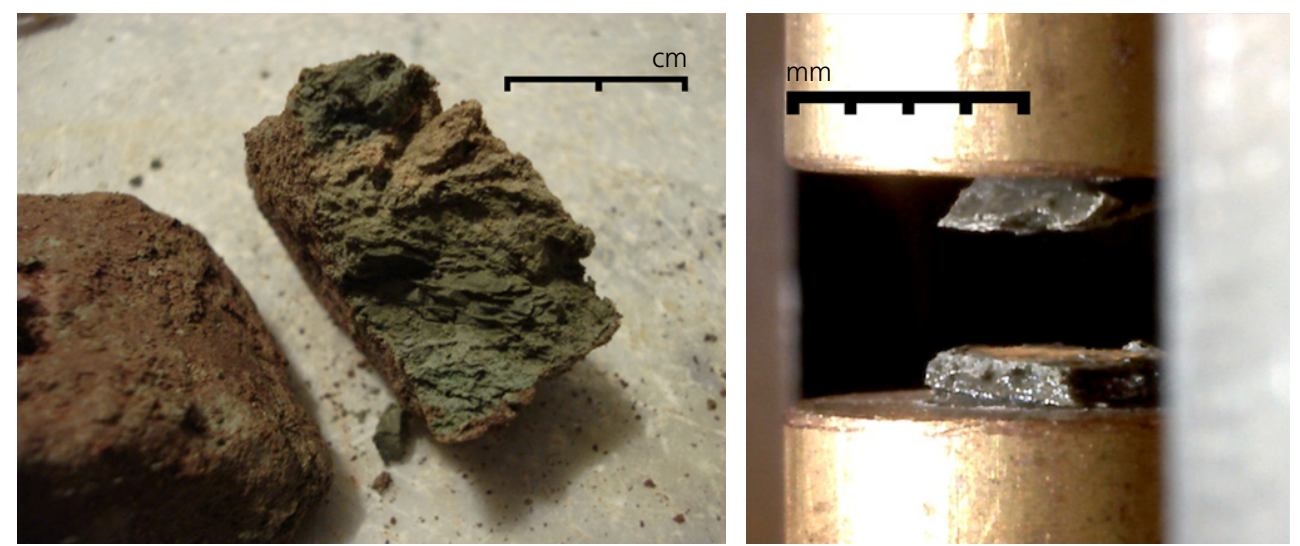

Fig. 1. (a) Mesostructure of PS clay; (b) pair of scales of SCM clay before testing

particle mounts by means of stiff mechanical parts. The sled is placed on a polished piece of stainless steel by means of a bearing system made up of three chrome steel balls and can be moved along the horizontal plane by means of the linear actuators. The upper particle is held by a holder placed at the end of the vertical loading arm, which applies the vertical load at the contact with the lower particle during shearing (Fig. 2 (d)). The forces are measured by means of high-resolution load cells (Fig. 2(e)) having a capacity of $100 \mathrm{~N}$.

In the modified version of the apparatus, the displacements are measured using three non-contact eddy current displacement sensors (Fig. 2(f)), which have a measuring range of $3 \mathrm{~mm}$ and a resolution of $10^{-5} \mathrm{~mm}$. The whole apparatus is located inside a Perspex chamber and the humidity conditions of this are controlled using a humidity controller that is able to regulate the relative humidity within a range between 15 and $85 \%$. A custom-made software is used both to input the control commands for force or displacement and record the data during testing. Two digital micro-cameras (Fig. 2(g)) are installed inside the Perspex chamber. These help to find the right location and orientation of the contact between the two loaded surfaces and to record images during each test.

\section{Materials tested}

The SCM and the PS scaly clays were block sampled from an outcrop in situ, after removal of a thick stratum of soil, at depths of about 3 and $1.5 \mathrm{~m}$ below ground level, respectively. The particular SCM clay sample used for these tests was characterised by a very high fissuring intensity (I6) and with fissures orientated at $45^{\circ}$ to the horizontal (F1-45) according to the F-ID classification chart of Vitone \& Cotecchia (2011). Also, it featured a very high clay fraction $(\mathrm{CF}=91 \%)$, medium activity $(A=0 \cdot 70)$ and high liquid limit $\left(w_{1}=97 \%\right)$. The void ratio was $0 \cdot 711$, with an average initial water content of $22.6 \%$ and a saturation degree $S=88 \cdot 1 \%$. As reported by Vitone \& Cotecchia (2011), the SCM clay was more generally characterised by a similar $\mathrm{CF}(91 \%)$, but lower activity $(A=0.57)$ and liquid limit $\left(w_{1}=81 \%\right)$ in their previous investigations. The SCM scaly clay includes small quantities of kaolinite and chlorite and a large amount of illite-smectite mixed layer clay minerals (around 80\%) with $50 \%$ of smectite, as measured by X-ray diffraction (Vitone \& Cotecchia, 2011). The SCM clay scales tested had an average thickness of $0.94 \mathrm{~mm}$ and length of $3.24 \mathrm{~mm}$.

The particular PS clay sample tested featured a lower fissuring intensity (I6/I5) and a set of fissures randomly orientated (F3). Its CF was lower $(\mathrm{CF}=45 \%)$, its content of silt and sand much higher [silt fraction $=30 \%$, sand fraction

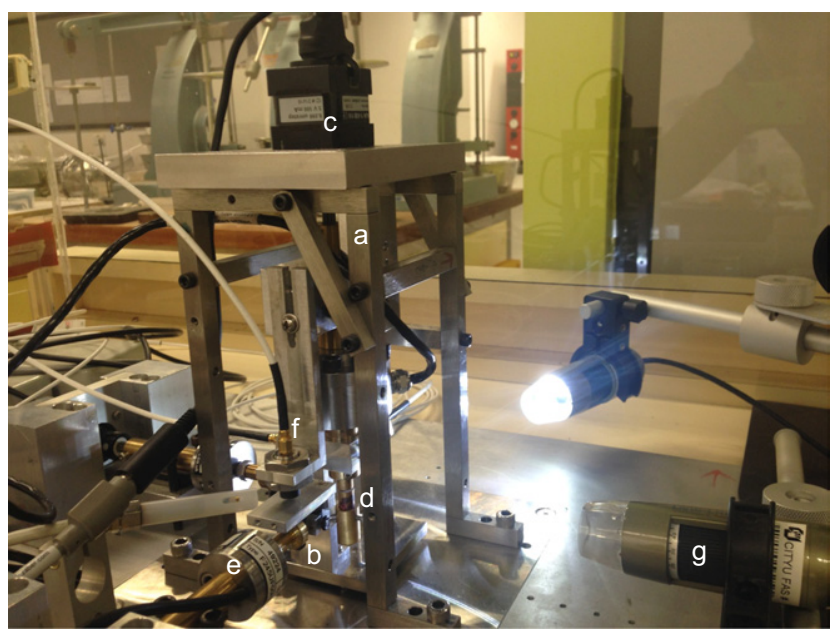

Fig. 2. Inter-particle loading apparatus: (a) loading frame; (b) stainless steel sled; (c) linear actuator; (d) clay scales during a test; (e) load cell; (f) eddy-current displacement sensor; (g) digital micro-camera

$(\mathrm{SF})=21 \%]$ and liquid limit lower $\left(w_{1}=60 \%\right)$ compared with the SCM clay sample, while the activity $(A=0.75)$ was also medium. The PS clay had a void ratio of 0.658 , an average initial water content of $24 \%$ and a high degree of saturation $S=99 \cdot 2 \%$. As outlined in Cotecchia et al. (2015), the upper unit of Paola Doce formation, where PS clay belongs to, more generally exhibits CFs within the range 19-55\%, sand fractions that are significant $(\mathrm{SF}=16-26 \%)$ and activities from medium to high $(A=0 \cdot 5-1)$. The results of an X-ray diffraction analysis on the PS clay showed that smectite is the dominant clay mineral present (around 70\%) with smaller quantities of illite and kaolinite (around 15\% each). The PS clay scales tested had an average thickness of $1.17 \mathrm{~mm}$ and length of $3.18 \mathrm{~mm}$.

\section{Testing procedures}

The clays were tested using both the inter-particle loading apparatus and the Bromhead ring shear apparatus. For the inter-scale tests, these were carried out applying either forces or displacements at the contact of two scales of clay mounted on stiff brass holders using a thin layer of super glue. All the test results were corrected by the compliance of the apparatus, including the glue used to mount the particles, and the friction of the sled. The structure of each clay scale was preserved in order to test them in conditions that were as close as possible to those in situ. The samples were prepared 
taking care of the scale shape, selecting the pieces of soil having a defined clay scale structure which was characterised by a flat shape so that two parallel faces could be tested, in order to minimise the components of force out of plane. Most of the tests were performed on scales taken directly from the undisturbed clay specimen at their natural water content. The scales would therefore have large suctions within them arising from: $(a)$ the fact that the block samples may not have been fully saturated (especially the SCM), (b) unloading due to sampling and (c) any drying of the scales during sample preparation and testing. Indeed, it is the suctions that would be largely responsible for the bulk strength of the scales allowing them to be handled and tested. It was therefore important to ensure that no significant component of this suction acted on the scale interfaces, which would affect the calculated angle of shearing resistance. One method used to check this was to spray a small amount of distilled water on the contact surfaces of some particle pairs. This was done immediately before loading avoiding softening of the particles due to significant dissipation of the suctions. As will be discussed later, no effects of the presence of water on the mechanical behaviour were observed.

The ring shear tests were carried out using two different procedures: a 'standard' one, in which the material was remoulded at a water content around $1.5 w_{1}$, and an 'alternative' one where portions of intact material were taken directly from the clay sample and placed inside the ring of the apparatus, orientating the existing fissures along the shearing direction. All the tests were performed shearing the samples at the minimum velocity allowed by the apparatus $(0.019 \mathrm{~mm} / \mathrm{min})$, after consolidation to maximum vertical effective stresses between 107 and $300 \mathrm{kPa}$.

\section{RESULTS}

\section{Compression behaviour at the scale contacts}

Of primary interest is the inter-scale shearing behaviour, but the initial normal loading data are presented for completeness. Figure 3 shows the results of the initial vertical compression stages for both the SCM and PS clays. In each test, the clay scales were compressed along the direction normal to the contact between the scales, using displacement

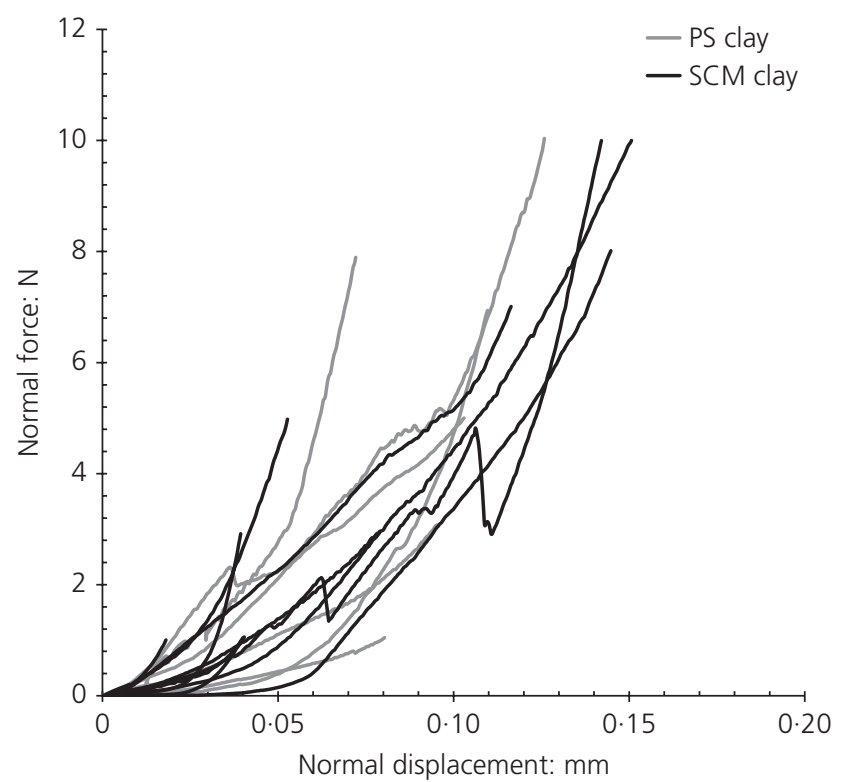

Fig. 3. Comparison between the compression curves for both SCM and PS clays rates between 0.2 and $0.8 \mathrm{~mm} / \mathrm{h}$, while the material was unconfined laterally. The behaviour typically observed is characterised by an elasto-plastic response that becomes stiffer with the increase of the normal displacement. The data are quite scattered, and it is likely that the response is sensitive to the scale geometry and surface morphology. However, it is not known what component of the displacement arises at the interface and what within the scales, so some of the measured values may result from the interface contact behaviour, especially because at the start of loading the behaviour is noticeably softer and it only stiffens at larger displacements. The stiffness of most of the curves at higher loads tends to a similar value, although some scale pairs exhibit softer behaviour. For displacements larger than $0.02 \mathrm{~mm}$, PS clay seems to be less compressible than the SCM clay, probably due to its lower CF and lower plasticity index.

Figure 4 shows the results of a test where two SCM clay scales were loaded up to $3 \mathrm{~N}$, then unloaded and reloaded reaching $3 \mathrm{~N}$ again. The test shows that the unloadingreloading behaviour is mainly reversible and that a similar displacement is reached on reloading to that before unloading, but the hysteresis loop is large. On unloading the vertical load never becomes negative, which again confirms that there could not have been a significant suction acting at the scale interface. This was observed for all the tests performed on both clays. This may well be because the scales were not fully saturated either due to the initial state of the blocks or because the suctions exceeded the air entry value, so that there was a lack of continuity of the fluid phase between the two scales that prevented a connection and consequent equilibrium between the hydraulic conditions within them.

\section{Shearing behaviour of the scale contacts}

Twenty-two shear tests were carried out on the SCM scaly clay and 14 on the PS clay, confined under normal loads between $1 \mathrm{~N}$ (the limit for accurate data in this apparatus) and $10 \mathrm{~N}$ and sheared applying displacement rates of between 0.02 and $0.08 \mathrm{~mm} / \mathrm{h}$. Figures 5 and 6 show the tangential force-displacement curves for the SCM and PS clays, respectively. In general, the tests were terminated

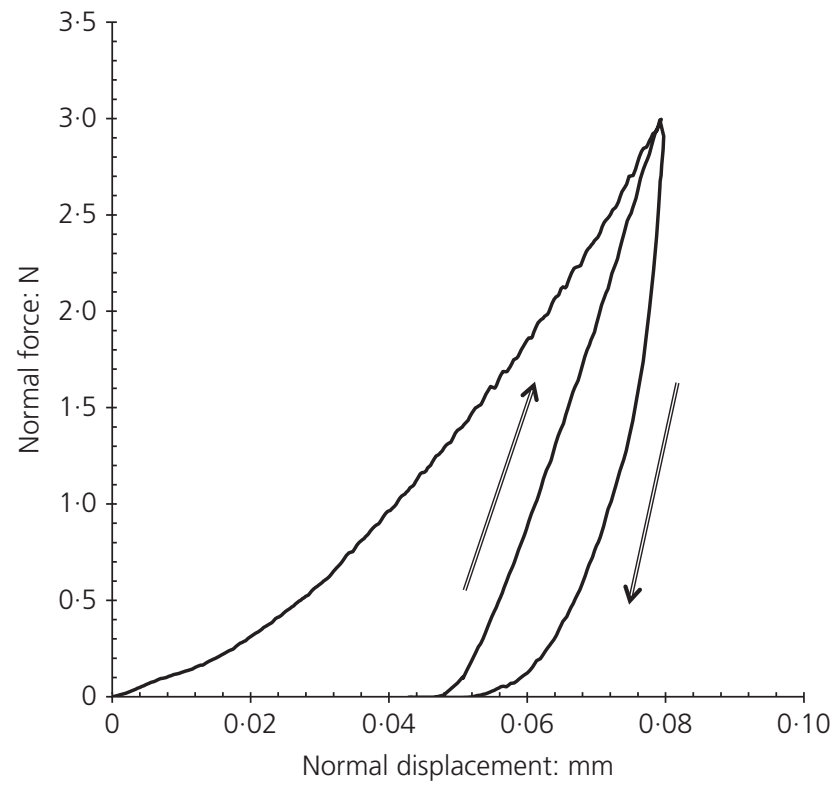

Fig. 4. Loading-unloading-reloading behaviour of SCM clay in compression 


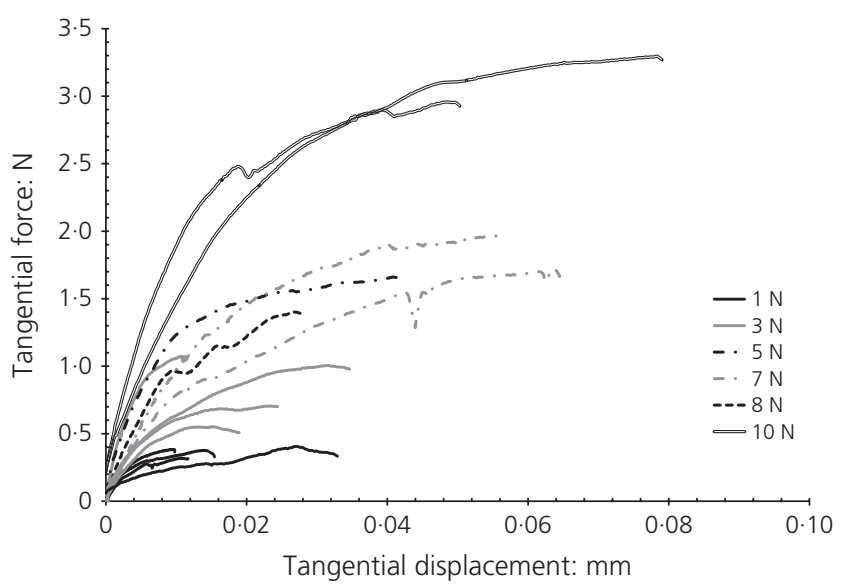

Fig. 5. Tangential force-displacement curves for SCM clay scales

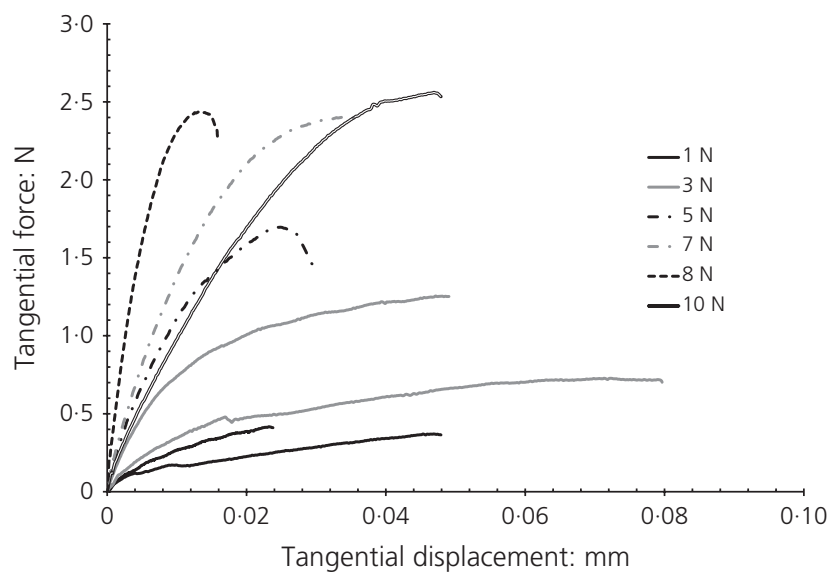

Fig. 6. Tangential force-displacement curves for PS clay scales

as soon as a constant tangential force was reached, but some tests were continued to larger displacements to check whether the measured force would degrade. Both graphs show that the two clays exhibit a similar behaviour in shearing, where the response becomes less stiff with the increase of the displacement until a steady state is reached. Also, the clay behaviour seems to be dependent on the applied vertical load during shearing. This dependence can be also observed in the tangential stiffnesses (Figs 7 and 8), which decrease with the increase of the displacement until it reaches values around zero, corresponding to the steady state. Some scatter can also be observed for tests carried out under the same confining loads, especially for the SCM clay.

Figure 9 illustrates the results of a cyclic shear test on a pair of SCM clay scales vertically confined under $3 \mathrm{~N}$. The slope of the unloading and reloading curves seems not to be affected by the increase of the number of loops and a degradation of the stiffness is not evident, although this was investigated for a small number of loops only. It is likely that if many cycles are carried out and large displacements accumulate the mobilised angle of shearing resistance would drop towards the residual, which would probably also affect the stiffness. Also, a slight decrease of friction coefficient can be observed between the steady state reached at small displacements $(0.02-0.04 \mathrm{~mm})$ and that after large displacements (over $0.1 \mathrm{~mm}$ ).

Figure 10 shows the results obtained for both SCM and PS clays plotted normalising the tangential load by means of the vertical load during each test. The continuous

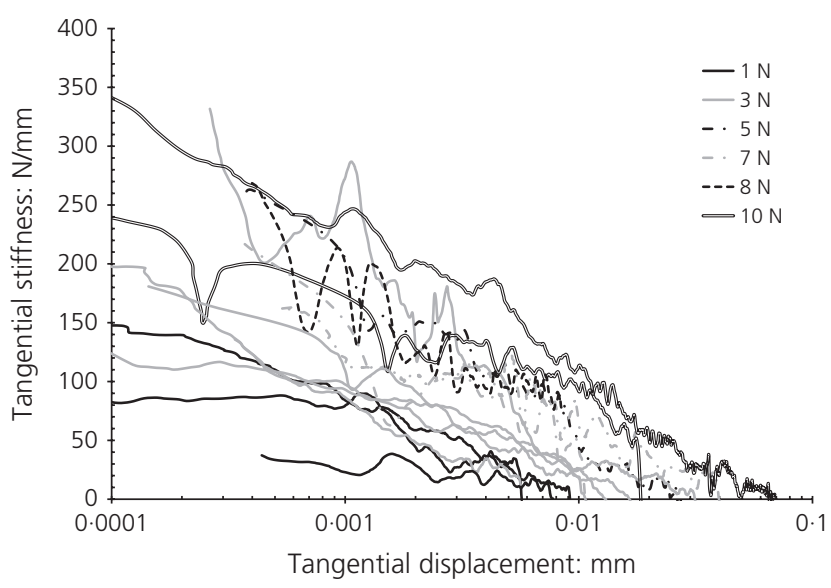

Fig. 7. Tangential stiffness-displacement curves for SCM clay scales

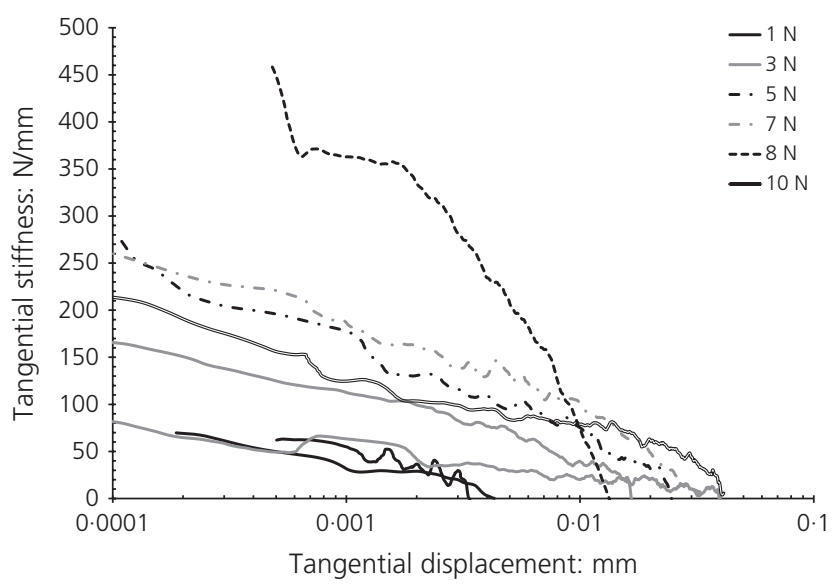

Fig. 8. Tangential stiffness-displacement curves for PS clay scales

lines represent the tests carried out under low vertical loads (1-3 N) while the dashed lines are for those under high forces $(5-10 \mathrm{~N})$. This shows that slightly higher friction coefficients are generally reached for tests under low confining forces and that the curves obtained from these tests have a higher slope (i.e. normalised tangential stiffness) compared with those tests performed under higher confining forces. Also, the SCM clay response appears stiffer than that of PS clay.

The failure envelopes for both SCM and PS clays are shown in Fig. 11. Small markers are used for those data obtained from tests performed spraying the clay scales using distilled water, while the large markers are for the remaining tests. The data for the two soils are remarkably similar, and both can be well represented with linear failure envelopes, despite the observation on Fig. 10 that the mobilised stress ratios at low vertical forces are slightly higher. The PS clay exhibits values of friction coefficient between the scales that are slightly larger than those for the SCM clay, which may be caused by the higher silt and sand fractions of this material. The presence or absence of the sprayed water also makes no clear difference, again indicating that suctions on the scale interfaces do not play any significant role. The absence of an intercept on the failure envelope is a further confirmation that there are no significant inter-scale suctions.

Another important feature of the data is that they are reasonably consistent. Considering that the horizontal orientation of the scales was random, this is an indication 


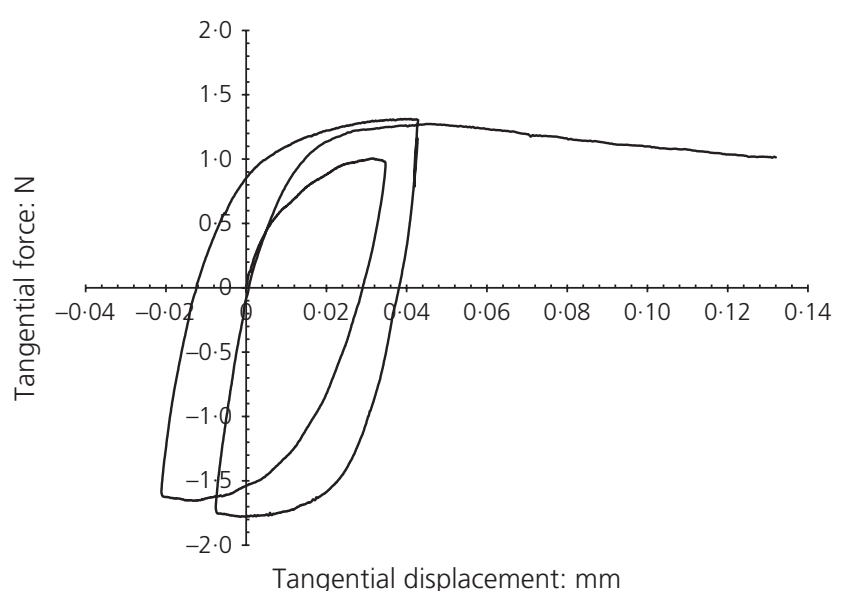

Fig. 9. Cyclic tangential force-displacement curves for a pair of SCM clay scales under a normal load of $3 \mathrm{~N}$

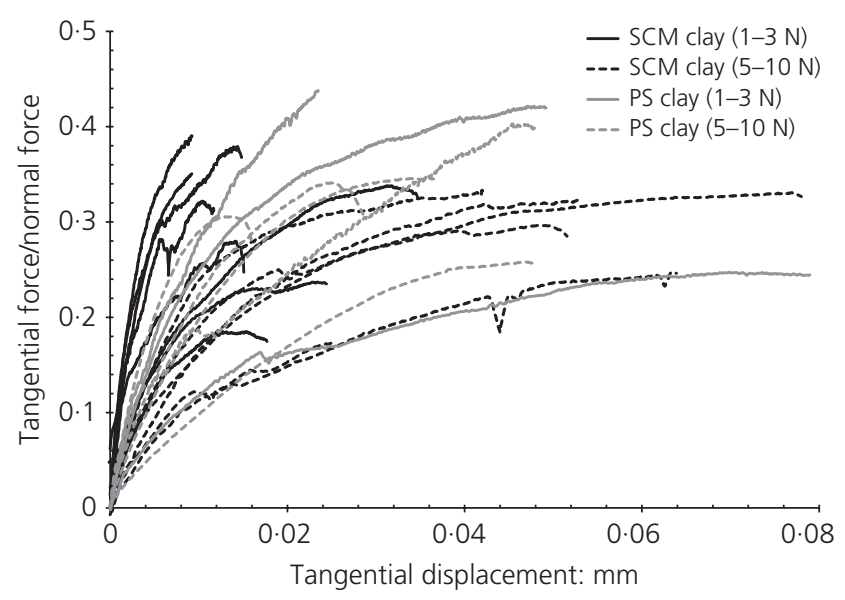

Fig. 10. Comparison between the normalised tangential loaddisplacement curves of both SCM and PS clays: continuous lines for normal loads 1-3 N, dashed lines for 5-10 N

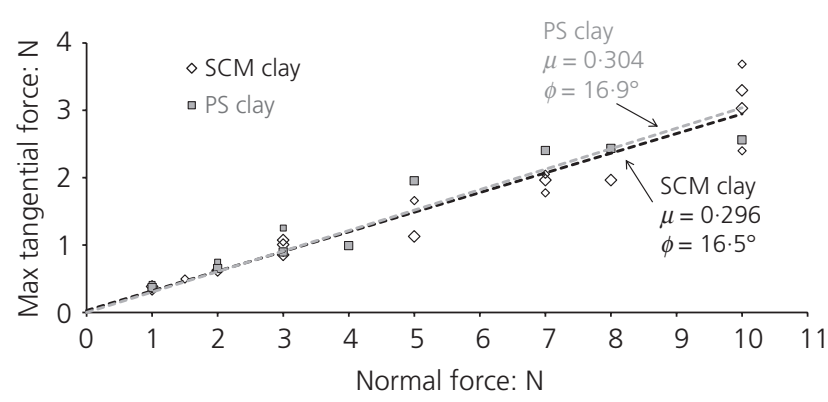

Fig. 11. Failure envelopes for both SCM and PS scaly clays (small markers - water sprayed onto scale surfaces)

there are unlikely to be different mobilised angles of shearing resistance in different directions.

\section{Comparisons with macro-scale test results}

Figures 12 and 13 illustrate the results of the tests carried out on SCM and PS clays, respectively, by means of the ring shear apparatus. The average residual friction angles obtained using the standard procedure, which involves the remoulding of the natural material, are slightly larger than those obtained from the alternative procedure. The values

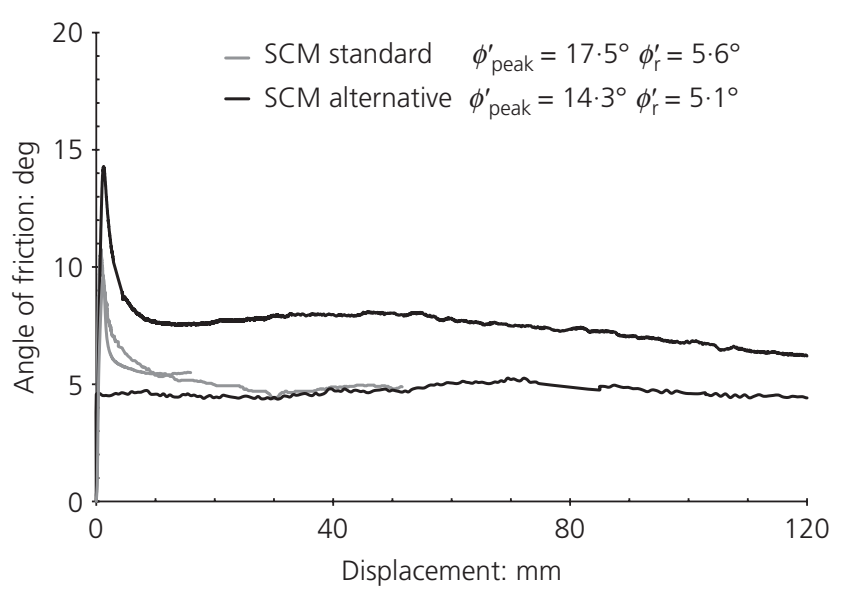

Fig. 12. Ring shear test results for the SCM scaly clay

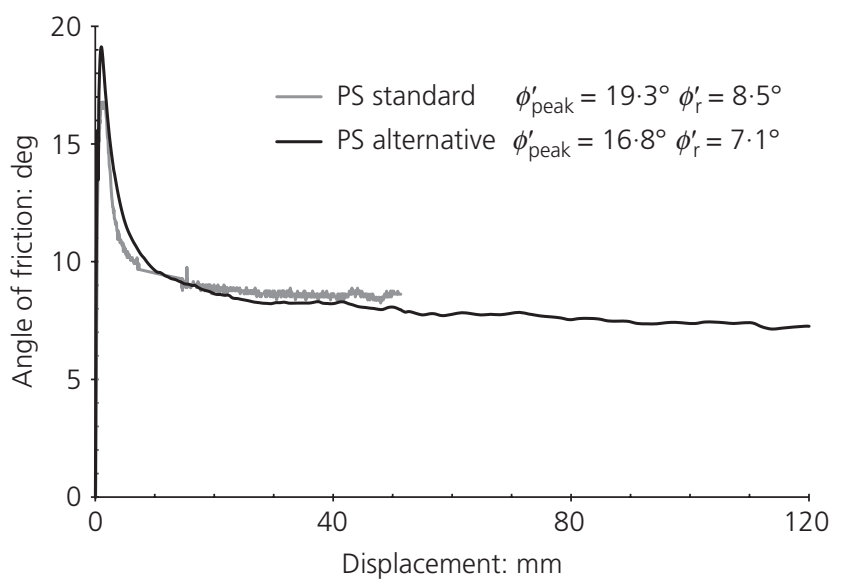

Fig. 13. Ring shear test results for the PS scaly clay

obtained are consistent with the correlations proposed by Lupini et al. (1981), which relate the residual friction angle with the $\mathrm{CF}$ and the plasticity index. The residual friction angles are low and the post-peak brittleness is pronounced, as is typical for southern Italian scaly clays (e.g. Tika, 1989; Fearon \& Coop, 2002). The residual angle for the less plastic PS clay is significantly higher than for the SCM. The tests using the alternative procedure indicate that the post-peak brittleness is similar for the intact soil and the reconstituted. Unfortunately, this post-peak behaviour could not be investigated in the inter-scale tests due to the limited stroke of the apparatus, but the slow decline of the tangential load at large displacements in Fig. 9 is probably the result of this brittleness.

Table 1 shows a summary of the friction angles measured on SCM and PS clays from the literature. Only the ring shear data obtained from the standard process are presented. It shows that the friction angles obtained from the inter-scale tests are much higher than the residual ones and they are close to the post-peak values determined through the triaxial tests, generally determined for the samples experiencing failure along a shear band that localised along the pre-existing fissures. They are also quite similar to the critical state values determined from tests on reconstituted samples and also the 'peak' values from the ring shear tests, although the latter would not be reliable peak strengths due to progressive failure which results from varying strains across the sample radius. This means that the clay platelets on the surface of the contacting scales are not flat and aligned. 
Table 1. Summary of the friction angles found here and in the literature for SCM and PS scaly clays

\begin{tabular}{l|l|l}
\hline Soil type & Testing device & Friction angle \\
\hline SCM clay & Triaxial apparatus* & $\begin{array}{l}\phi_{\text {peak }}^{\prime}=25^{\circ}, \phi_{\text {post-peak }}^{\prime}=12-20^{\circ} \\
\phi_{\text {cs }}^{*}=18^{\circ} \\
\phi_{\text {peak }}^{\prime}=17 \cdot 5^{\circ}, \phi_{\mathrm{r}}^{\prime}=5 \cdot 6^{\circ} \\
\phi=16 \cdot 5^{\circ}\end{array}$ \\
$\begin{array}{l}\text { Inter-particle loading } \\
\text { apparatus }\end{array}$ & $\begin{array}{l}\text { Triaxial apparatus } \dagger \\
\text { PS clay }\end{array}$ & $\begin{array}{l}\phi_{\text {peak }}^{\prime}=21-25^{\circ}, \phi_{\text {post-peak }}^{\prime}=13-20^{\circ} \\
\phi_{\text {cs }}^{*}=18^{\circ} \\
\phi_{\text {peak }}^{\prime}=19 \cdot 3^{\circ}, \phi_{\mathrm{r}}^{\prime}=8 \cdot 5^{\circ} \\
\phi=16 \cdot 9^{\circ}\end{array}$ \\
\hline
\end{tabular}

*Data from Vitone \& Cotecchia (2011).

$\dagger$ Data from Cotecchia et al. (2015).

Despite their appearance and genesis, a strength that is much higher than the residual is mobilised on the clay scales.

\section{CONCLUSIONS}

This work has focused on the inter-scale behaviour of two natural scaly clays from Italy, which was studied by means of a custom-made inter-particle loading apparatus. The results showed that despite the lower clay content and lower plasticity of the PS clay, the mobilised inter-scale angle of shearing resistance is very similar to that of the clay from SCM. A comparison between the micro-scale test results and those obtained from tests on macro-scale samples using the ring shear and triaxial apparatuses showed that the strength measured on the surface between two clay scales is far from the residual strength, and more similar to post-peak or critical state strengths, so it is unlikely that there is alignment of the clay platelets on the surfaces of the scales.

\section{ACKNOWLEDGEMENTS}

The authors thank Professor Federica Cotecchia and Dr G. Pedone for providing the scaly clays tested in this research project. They are also grateful to Dr Béatrice Baudet for the use of the ring shear apparatus at the University of Hong Kong. The technicians of City University of Hong Kong, Mr Y.H. Tsang and Mr C.K. Lai and Mr E. Miccoli of Technical University of Bari are also acknowledged for their help, along with Mr V. Roca and Miss F. Carone who performed the ring shear tests at the Technical University of Bari. This work was fully supported by a grant from the Research Grants Council of the Hong Kong Special Administrative Region, China (Project No. CityU 112712).

\section{REFERENCES}

Cavarretta, I., Coop, M. R. \& O'Sullivan, C. (2010). The influence of particle characteristics on the behaviour of coarse grained soils. Géotechnique 60, No. 6, 413-423, http://dx.doi.org/ 10.1680/geot.2010.60.6.413.
Cotecchia, F. \& Santaloia, F. (2003). Compression behaviour of structurally complex marine clays. Proceedings of the Nakase memorial symposium on 'soft ground engineering in coastal areas', Yokosuka, Japan, pp. 63-72.

Cotecchia, F., Vitone, C., Santaloia, F., Pedone, G. \& Bottiglieri, O. (2015). Slope instability processes in intensely fissured clays: case histories in the Southern Apennines. Landslides 12, No. 5, 877-893.

Croce, A. (1971). Opening address. Proceedings of the international symposium on the geotechnics of structurally complex formations, Capri, vol. 2, pp. 148-151.

Cundall, P. A. \& Strack, O. D. L. (1979). A discrete numerical model for granular assemblies. Géotechnique 29, No. 1, 47-65, http://dx.doi.org/10.1680/geot.1979.29.1.47.

Dazzaro, L. \& Rapisardi, L. (1996). Schema geologico del margine appenninico tra il F.Fortore e il F.Ofanto. Mem. della Soc. Geol. Ital. 51, No. 1, 143-147 (in Italian)

Esu, F. (1977). Behaviour of slopes in structurally complex formations. Proceedings of the international symposium on the geotechnics of structurally complex formations, Capri, vol. 2, pp. 292-304.

Fearon, R. \& Coop, M. R. (2002). The influence of landsliding on the behaviour of a structurally complex clay. Q. J. Engng Geol. Hydrogeol. 35, No. 1, 25-32.

Horn, H. M. \& Deere, M. S. (1962). Frictional characteristics of minerals. Géotechnique 12, No. 4, 319-335, http://dx.doi.org/ 10.1680/geot.1962.12.4.319.

Lupini, J. F., Skinner, A. E. \& Vaughan, P. R. (1981). The drained residual strength of cohesive soils. Géotechnique 31, No. 2, 181-213, http://dx.doi.org/10.1680/geot.1981.31. 2.181 .

Nakata, Y., Hyde, A. F. L., Hyodo, M. \& Murata, H. (1999). A probabilistic approach to sand crushing in the triaxial test. Géotechnique 49, No. 5, 567-583, http://dx.doi.org/10.1680/geot. 1999.49.5.567.

Nardelli, V. \& Coop, M. R. (2015). An experimental investigation of the micromechanical behaviour of cemented sand particles. Proceedings of the TC105 ISSMGE international symposium on geomechanics from micro to macro, Cambridge, UK, vol. 2, pp. 1013-1018.

Senetakis, K. \& Coop, M. R. (2014). The development of a new micro-mechanical inter-particle loading apparatus. Geotech. Test. J. 37, No. 6, 1028-1039.

Senetakis, K., Coop, M. R. \& Todisco, M. C. (2013). Tangential load-deflection behaviour at the contacts of soil particles. Géotech. Lett. 3, No. 2, 59-66, http://dx.doi.org/10.1680/ geolett.13.00019.

Skinner, A. E. (1969). A note on the influence of interparticle friction on shearing strength of a random assembly of spherical particles. Géotechnique 19, No. 1, 150-157, http://dx.doi.org/ 10.1680/geot.1969.19.1.150.

Tika, T. M. (1989). The effect of fast shearing on the residual strength of soils. $\mathrm{PhD}$ thesis, University of London, London, UK.

Vannucchi, P., Maltman, A., Bettelli, G. \& Clennell, M. (2003). On the nature of scaly clay fabric and scaly clay. J. Struct. Geol. 25, No. 5, 673-688.

Vitone, C. \& Cotecchia, F. (2011). The influence of intense fissuring on the mechanical behaviour of clays. Géotechnique 61, No. 12, 1003-1018, http://dx.doi.org/10.1680/geot.9. P.005.

Vitone, C., Viggiani, G., Cotecchia, F. \& Hall, S. A. (2013). Localized deformation in intensely fissured clays studied by 2D digital image correlation. Acta Geotech. 8, No. 3, $247-263$.

\section{HOW CAN YOU CONTRIBUTE?}

To discuss this paper, please submit up to 500 words to the editor at journals@ice.org.uk. Your contribution will be forwarded to the author(s) for a reply and, if considered appropriate by the editorial board, it will be published as a discussion in a future issue of the journal. 